\title{
In-service Teachers' Intelligibility and Pronunciation Adjustment Strategies in English Language Classrooms
}

\author{
Hsueh Chu Chen ${ }^{1}$ \\ ${ }^{1}$ Department of Linguistics and Modern Language Studies, The Hong Kong Institute of Education, Hong Kong, \\ China \\ Correspondence: Hsueh Chu Chen, Department of Linguistics and Modern Language Studies, The Hong Kong \\ Institute of Education, 10 Loping Rd., Taipo, New Territories, Hong Kong. Tel: 852-2948-7376. E-mail: \\ hsuehchu@ied.edu.hk
}

Received: January 17, 2016 Accepted: February 26, 2016 Online Published: March 1, 2016

doi: $10.5539 /$ elt.v9n4p30

URL: http://dx.doi.org/10.5539/elt.v9n4p30

\begin{abstract}
A realistic goal of pronunciation teaching in the second language context is to acquire comfortably intelligible rather than native-like pronunciation. To establish a set of teaching and learning priorities necessary for English teachers and students whose first language is Chinese, the purposes of this study are three fold: (1) Identify the pronunciation aspects that are crucial for intelligible pronunciation in actual second language (L2) Hong Kong (HK) and foreign language mainland (ML) China classrooms from in-service teachers' points of view; (2) Investigate how teachers help their students successfully understand English classroom input through teachers' self-reflection on which aspects of their own pronunciation they modify and adapt to make classroom discourse intelligible to students; and (3) explore the most frequently taught pronunciation aspects and the most frequently used pronunciation teaching strategies used by teachers to teach pronunciation in English classrooms. Forty-seven questionnaires were collected and analysed from in-service teachers in primary schools. Four teachers were invited to attend follow-up interviews. In order to further investigate the application of adaptation strategies and pronunciation teaching strategies in real classroom settings, eight classroom videos were collected. The data were triangulated allowing for cross checking. The findings will not only help frontline teachers become self-aware of their own pronunciation, rectify students' recurrent difficulties in using phonological features, and improve mutual intelligibility in English language classrooms but also help explore the ways to integrate phonology courses and pronunciation teaching in second/foreign language teaching and teacher education.
\end{abstract}

Keywords: pronunciation teaching, interlanguage phonology, foreign accent, teacher talk

\section{Introduction}

In the 1970s, pronunciation teaching was considered a priority in second language (L2) classrooms, and mastery of native-like pronunciation was widely deemed as the goal of pronunciation teaching. At that time, minimal-pair drills and imitation of appropriate models were widely used in language classes to enhance students' pronunciation (Saito \& Lyster, 2012). However, this native-like assumption was not well supported by L2 speech research evidence. Saito and Lyster (2012) point out that (a) "L2 speech is typically foreign-accented, mainly due to the interaction between the learners' age and first language (L1)" (e.g. Piske, MacKay, \& Flege, 2001), and (b) "very few adult learners achieve accent-free pronunciation in their L2" (p. 3). More recently, the ultimate goal of L2 pronunciation learning has shifted to "intelligible" pronunciation that can foster successful L2 communication. Instead of achieving native-like pronunciation, researchers and practitioners have now shifted their focus to which pronunciation features can influence intelligibility and comprehensibility in L2 communications (Derwing \& Munro, 2005; Field, 2005; Setter \& Jenkins, 2005). More recently, attaining intelligibility for the purpose of successful L2 communication, rather than native-like pronunciation, has become a more realistic goal for L2 learners (Derwing \& Munro, 2005; Levis, 2005; Setter \& Jenkins, 2005). To this end, the adjustment strategies non-native English (NNE) interlocutors employ to make their L2 speech more intelligible are worth studying.

Many teachers are uncomfortable dealing with pronunciation, particularly given the multilingual nature of most English as a second language (ESL) classes (Breitkreutz, Derwing, \& Rossiter, 2001). Most instructors have not 
had any specific training for the teaching of pronunciation; neither have they had much in the way of linguistic training in phonetics and phonology (Murphy, 1997). Although second-language users are often able to modify their pronunciation to the extent that native listeners find their productions significantly easier to understand (Derwing et al., 1997; Derwing et al., 1998), total elimination of an accent is not a realistic goal. In a comparison of segmental versus suprasegmental approaches to pronunciation, Derwing et al. (1998) advocated an approach to pronunciation instruction in which segments are included but prosodic elements receive the major emphasis.

\subsection{Pronunciation-Specific Adjustment}

To make speech more intelligible, most language teachers are inclined to slow down their speech in class, particularly for low achievers or young learners. In L1 speech literature, pronunciation-specific adjustment strategies used by mothers to talk with their babies have been elaborated by many studies, which include using exaggerated intonation, slow speed, higher pitch, and simplified prosody, all of which were claimed to better attract infants' attention so as to boost understanding of their mother's speech (Yule, 2010; Fernald \& Kuhl, 1987). In L2 speech literature, however, the pronunciation adjustment strategies that may enhance mutual intelligibility between interlocutors is rather limited. Chaudron (1988), having investigated teacher talk for a long time and summarized some research results on teacher talk, proposed teacher talk in language classrooms tends to show the following modifications: 1) rate of speech appears to be slower, 2) pauses, which may be evidence of the speaker planning more, are possibly more frequent and longer, 3) pronunciation tends to be exaggerated and simplified, 4) vocabulary use is more basic, 5) degree of subordination is slower, 6) declaratives and statements are used more often than questions, and 7) teachers may self-repeat more frequently.

Saito and van Poeteren (2012) conducted a study examining how experienced teachers adapt, in particular, their pronunciation features in order to boost mutual intelligibility and facilitate their students' learning in L2 classrooms (i.e. pronunciation-specific adjustment strategies). This study identified a range of pronunciation-specific teacher talk techniques used based on the teachers' self-reports in a retrospective manner. The results of this study demonstrated that experienced teachers consciously or intuitively make efforts to adjust their pronunciation in order to boost the classroom intelligibility. Many experienced teachers tend to "slow down their L2 speech and clearly enunciate each word. Furthermore, the results established that 44 teachers in total reported adjustment strategies by avoiding assimilation/liaison, contracting words, and speaking with more pause and repetition, which by corollary makes lexical and sentence boundaries in L2 input salient and clearer to students" (p. 379).

While many studies have attempted to investigate how pronunciation is taught in classroom settings and which pronunciation features most contribute to speech intelligibility (e.g. Derwing \& Munro, 2005; Levis, 2005; Setter \& Jenkins, 2005), there appears to be fewer studies that deal with pronunciation-specific adjustment strategies, particularly in classroom settings in L2 speech literature. The current study is proposed to further examine pronunciation-specific adjustment strategies employed by non-native English teachers as pedagogic tools in L2 or foreign language classroom settings to enhance mutual intelligibility and facilitate their students' learning.

\subsection{Comparisons of Hong Kong and Mainland Teachers}

Hong Kong is a multilingual society, so non-native English speakers (NNS) versus NNS communication in English is commonly observed in ESL classrooms. There is not enough research that considers pronunciation teaching and modification strategies by comparing teachers from varying linguistic backgrounds, such as Hong Kong (L1 is Cantonese) and mainland China (L1 is Mandarin), as well as from various learning environments, for example, ESL in Hong Kong, and English as a foreign language (EFL) in mainland China. In particular, the process of early literacy education in Mainland China and Hong Kong differs. Mainland Chinese teachers use Pinyin orthographic representations as a pedagogical aid. Because students expose to Pinyin in their early age, it is believed to foster the development of phonological awareness (Read et al, 1986). When EFL is introduced in school, explicit training in the International phonetical alphabet (IPA) or phonics instruction is sometimes used in classroom teaching to enhance segmental pronunciation. These Chinese EFL students can be assumed to have developed phonological awareness skills in L1 Chinese to apply to English when students are doing the task of learning to read. On the contrary, Hong Kong Chinese teachers teach children how learn to read the logographic Chinese script without Pinyin. Each orthographic Chinese character and its pronunciation are learnt by rote. When English as an L2 is introduced in school, a whole-word reading approach is commonly taken (Cheung, 1999). Therefore, Hong Kong Chinese generally learn English without extensive exposure to explicit phonological awareness training, which would possibly lead to their phonological awareness under developed for best alphabetic decoding.

It would be of great value to determine whether and in what ways English teachers with various first-language 
dialects and various learning/teaching experiences in English-speaking regions tackle English pronunciation teaching/modification strategies. To establish a set of teaching and learning priorities necessary for ESL/EFL teachers and students whose L1 is Chinese, the purposes of this study are three fold:

1) Identify the pronunciation aspects that are crucial for intelligible pronunciation in actual HK and ML English classrooms from in-service teachers' points of view;

2) Investigate how teachers help their students successfully understand English classroom input through teachers' self-reflection on which aspects of their own pronunciation they modify and adapt to make classroom discourse intelligible to students; and

3) Explore the most frequently taught pronunciation aspects and the most frequently used pronunciation teaching strategies used by teachers to teach pronunciation in English classrooms.

These findings will not only inform teachers of how to scaffold students' pronunciation learning and boost mutual intelligibility in ESL/EFL classrooms, but will also assist to advocate for and increase students' awareness of the essential importance of acquiring accuracy in English pronunciation.

\section{Method}

Forty-seven questionnaires were collected and analysed from in-service teachers in primary schools in Hong Kong and mainland China; 25 were from Hong Kong and 22 were from mainland China. Their teaching experiences ranged from 2 to 31 years; 27 teachers had less than five years of experience, nine teachers had between 6 and 15 years of experience, and 11 teachers had between 16 and 31 years of experience. Four teachers were invited to attend follow-up interviews on a voluntary basis. In order to further investigate the application of adaptation strategies and pronunciation teaching strategies in real classroom settings, eight classroom videos were collected. The data were well rounded and triangulated allowing for cross checking.

\subsection{Questionnaire}

Forty-seven participants were first requested to fill out their personal information in order to seek information on teachers' backgrounds and teaching experience, what pronunciation features were taught/practiced, how pronunciation was taught, and what difficulties teachers experienced in pronunciation teaching. The questionnaire consisted of five parts (please see Appendix I):

Part 1 of the questionnaire covered the most common pronunciation-related adjustment strategies. The most common pronunciation-related adjustment strategies were revised from Saito and van Poeteren (2012). The participants were asked to indicate what pronunciation-related adjustment strategies they use in the classroom and how often they use them to make the classroom discourse more intelligible to students (e.g. speech rate modification, word-level enunciation).

Part 2 covered the pronunciation features of their students that may impede the intelligibility in classrooms. A list of the most common pronunciation features that may impede intelligibility between teachers and students in L2 classrooms was provided. The feature analysis was made based on forty sets of reading aloud data compiled by the author and her colleagues (2014) from the "Spoken Corpus of the English of Hong Kong and Mainland Chinese learners".

Part 3 covered the common pronunciation teaching strategies. The common pronunciation teaching strategies were revised from Burgess and Spencer (2000). Teachers were required to indicate what strategies they use and how often they use the strategies in their teaching of pronunciation. A list of the most common pronunciation remedial strategies used by teachers in language lessons was provided (e.g. choral repetition, minimal pair drills, and pronunciation-focused recast).

Part 4 covered the aspects of pronunciation that are taught in language lessons. A list of the phonological features taught during language lessons was revised from Burgess and Spencer (2000).

Part 5 covered teachers' teaching styles and beliefs about teaching pronunciation. One open-ended question was followed by the five questions shown above. That is, how do they think their teaching of pronunciation has changed over their career?

\subsection{Follow-Up Interviews}

Four teachers were invited to conduct the follow-up interviews on a voluntary basis. All the questions were elaborations and clarifications based on the first four parts shown in the questionnaire.

\subsection{Classroom Video Analyses}

The main foci of these observations were on how the teachers used the pronunciation-related adjustment 
strategies and the pronunciation teaching strategies in the classrooms. Eight sessions of classroom observation were conducted to examine whether the participants' retrospective self-reports in the questionnaire truly reflected their actual teaching. Among the eight teachers, four were from mainland China and the other four were from Hong Kong.

\section{Results}

In the following section, we will first report the questionnaire results. Among five parts of the questionnaire items, in addition to reporting the descriptive statistics and $t$-test between Hong Kong and mainland teacher groups, the follow-up interview results from four teachers will be provided as supporting evidence for the questionnaire. Next, eight sessions of video analyses will be summarized.

\subsection{Questionnaire and Interview Results}

\subsubsection{Part 1: The Most Common Pronunciation-Related Adjustment Strategies}

Based on the results of the questionnaire, significant differences $\left({ }^{*} p<.05\right)$ were observed in the use of the following six adaptation strategies: "speech rate modification", "segmental-level enunciation", "word stress emphasis", "syllabification modification", "cognates strategy", and "repetition". It is obvious in Table 1 that teachers from ML use the six above-mentioned adaptation strategies significantly more often than HK teachers.

For English teachers in ML, the three most frequently used adjustment strategies are "repetition" $(\mathrm{M}=4.45)$, "speech rate modification" ( $M=4.18)$, and "segmental-level enunciation" $(M=4.18)$, while for English teachers in $\mathrm{HK}$, the three most frequently used adjustment strategies are "contraction avoidance" $(\mathrm{M}=3.88)$, "sentence stress emphasis" (M=3.88), and "repetition" $(\mathrm{M}=3.84)$.

Table 1. The most common pronunciation-related adjustment strategies teachers use to enhance the mutual intelligibility in an L2 classroom

\begin{tabular}{|c|c|c|c|c|c|}
\hline & Group & $\mathrm{M}$ & SD & $\mathrm{t}$ & $\begin{array}{l}\text { Sig. } \\
\text { (2-tailed) }\end{array}$ \\
\hline \multirow{2}{*}{ 1. Speech rate modification } & HK & 3.40 & 1.23 & -2.41 & $.020 *$ \\
\hline & ML & 4.18 & 0.96 & & \\
\hline \multirow{2}{*}{ 2. Word-level enunciation } & HK & 3.40 & 1.04 & -1.53 & 0.13 \\
\hline & ML & 3.86 & 0.96 & & \\
\hline \multirow{2}{*}{ 3. Segmental-level enunciation } & $\mathrm{HK}$ & 3.20 & 1.23 & -3.28 & $.002 *$ \\
\hline & ML & 4.18 & 0.73 & & \\
\hline \multirow{2}{*}{ 4. Contraction avoidance } & HK & 3.88 & 1.42 & 0.26 & 0.80 \\
\hline & ML & 3.77 & 1.41 & & \\
\hline \multirow{2}{*}{ 5. Assimilation, elision, linking avoidance } & $\mathrm{HK}$ & 3.00 & 1.29 & 0.40 & 0.69 \\
\hline & ML & 2.86 & 0.99 & & \\
\hline \multirow{2}{*}{ 6. Fluency modification } & HK & 3.60 & 1.23 & 0.03 & 0.98 \\
\hline & ML & 3.59 & 0.96 & & \\
\hline \multirow{2}{*}{ 7. Intonation emphasis } & $\mathrm{HK}$ & 3.42 & 1.28 & -2.02 & 0.05 \\
\hline & ML & 4.14 & 1.13 & & \\
\hline \multirow{2}{*}{ 8. Sentence stress emphasis } & HK & 3.88 & 0.97 & -0.41 & 0.68 \\
\hline & ML & 4.00 & 1.02 & & \\
\hline \multirow{2}{*}{ 9. Oral gestures display } & HK & 3.40 & 1.19 & -1.35 & 0.19 \\
\hline & ML & 3.86 & 1.17 & & \\
\hline \multirow{2}{*}{ 10. Word stress emphasis } & HK & 3.32 & 1.22 & -2.22 & $.032 *$ \\
\hline & ML & 4.00 & 0.82 & & \\
\hline \multirow{2}{*}{ 11. Syllabification modification } & HK & 3.00 & 1.19 & -2.48 & $.017 *$ \\
\hline & ML & 3.82 & 1.05 & & \\
\hline \multirow{2}{*}{ 12. Cognates strategy } & $\mathrm{HK}$ & 2.68 & 1.31 & -2.24 & $.030 *$ \\
\hline & ML & 3.45 & 1.01 & & \\
\hline \multirow{2}{*}{ 13. Repetition } & HK & 3.84 & 1.03 & -2.32 & $.025 *$ \\
\hline & ML & 4.45 & 0.74 & & \\
\hline
\end{tabular}


According to the interviews, most of the teachers do not think the features impede the intelligibility in the classroom very much because they have become very familiar with their students' accents. Four extracts from each teacher (HK-T1, HK-T2, ML-T1, and ML-T2) are listed below to support the figures in Table 1.

HK-T1: Sometimes, I will slow down my speech a bit. I try not to link my words, avoid assimilation, and I just pronounce each [word] individually first and then link them together.

I think stress carries more meaning when we express ourselves because we emphasize the important thing and information in a sentence and we tend to ignore some function words and prepositions. I tend to stress on the important content words. For example, I will say the homework will [be] DUE NEXT MONDAY. I will pause properly and stress the important words.

HK-T2: I will pick first language to help low achievers, but for those more capable ones, I won't choose this method. I prefer body language, repetition, or maybe I will slow down my speed.

ML-T1: I will try to slow down confusing part[s] that I thought when I talk to the students. I think most of the times I just slow down the speed and sometimes stress certain words, which I think will affect the understanding.

ML-T2: First, [I] slow down my speaking rate and ask them to repeat after me and check if they get what I am talking about. I will also use word-level enunciation and segmental-level enunciation. I will also write down the syllables on the blackboard and ask them to pronounce it by themselves. I also avoided the contraction, assimilation, elision, and linking because my students are too young. Even if I use some common contractions like "isn't", I will stress this part and tell them it is a contraction explicitly.

\subsubsection{Part 2. The Pronunciation Features of Students That May Impede the Intelligibility in Classrooms}

Teachers' responses to Part 2 of the questionnaire revealed that the features compiled by the researchers are quite common to their students in both ML and HK. Regarding the extent to which the features impede intelligibility, most of the teachers did not think the features impede the intelligibility in their classrooms. Based on the result, the mean score of the features were mainly distributed between 2 (seldom) and 3 (sometimes), and the mean score of all listed features was below 4 (often). This phenomenon was also confirmed by some teachers in the follow-up interview.

Table 2 shows that the top three features that HK teachers think will most impede intelligibility are "voiced $\mathrm{TH} / \mathrm{d} /$ is pronounced as/d/" $(\mathrm{M}=3.60)$, "syllable-timed rhythm" $(\mathrm{M}=3.56)$, and "deletion of final /1/" $(\mathrm{M}=3.48)$. For ML teachers, the top three features that impede intelligibility are "syllable-timed rhythm" $(\mathrm{M}=3.27)$, "inappropriate sentence stress" ( $\mathrm{M}=3.23)$ and "absence of linking" $(\mathrm{M}=3.23)$.

Table 2. The pronunciation features that may impede intelligibility in classrooms

\begin{tabular}{|c|c|c|c|c|c|}
\hline & Group & Mean & SD & $\mathrm{t}$ & Sig.(2-tailed) \\
\hline \multirow{2}{*}{ 1. Absence of contrasts between long and short vowels } & HK & 3.12 & 1.01 & \multirow{2}{*}{1.24} & \multirow{2}{*}{0.22} \\
\hline & ML & 2.73 & 1.16 & & \\
\hline \multirow{2}{*}{ 2. Absence of contrast between /Q/and/e/ } & HK & 3.24 & 0.97 & \multirow{2}{*}{1.78} & \multirow{2}{*}{0.09} \\
\hline & ML & 2.73 & 1.03 & & \\
\hline \multirow{2}{*}{ 3. Shorting the diphthongs } & HK & 3.2 & 1.16 & \multirow{2}{*}{1.66} & \multirow{2}{*}{0.11} \\
\hline & ML & 2.65 & 1.04 & & \\
\hline \multirow{2}{*}{ 4.Absence of reduced vowel in unstressed syllables } & HK & 3.13 & 1.15 & \multirow{2}{*}{2.99} & \multirow{2}{*}{$0.01 *$} \\
\hline & ML & 2.2 & 0.83 & & \\
\hline \multirow{2}{*}{ 5. Voiced $\mathrm{TH} / \mathrm{D} /$ is pronounced as $/ \mathrm{z} /$} & HK & 3.08 & 1.38 & \multirow{2}{*}{0.87} & \multirow{2}{*}{0.39} \\
\hline & ML & 2.74 & 1.2 & & \\
\hline \multirow{2}{*}{ 6. Voiced $\mathrm{TH} / \mathrm{D} /$ is pronounced as $/ \mathrm{d} /$} & HK & 3.6 & 1.26 & \multirow{2}{*}{2.87} & \multirow{2}{*}{$0.01 *$} \\
\hline & ML & 2.48 & 1.4 & & \\
\hline \multirow{2}{*}{ 7. Voiceless $\mathrm{TH} / \mathrm{T} /$ is pronounced as/f/ } & HK & 3.44 & 1.33 & \multirow{2}{*}{3.18} & \multirow{2}{*}{$0.00 * *$} \\
\hline & ML & 2.17 & 1.25 & & \\
\hline \multirow{2}{*}{ 8. Voiceless $\mathrm{TH} / \mathrm{T} /$ is pronounced as $/ \mathrm{t} /$} & HK & 2.67 & 1.34 & \multirow{2}{*}{1.81} & \multirow{2}{*}{0.08} \\
\hline & ML & 1.93 & 1.03 & & \\
\hline 9. Voiceless $\mathrm{TH} / \mathrm{T} /$ is pronounced as $/ \mathrm{s} /$ & HK & 2.33 & 1.37 & -1.21 & 0.24 \\
\hline
\end{tabular}




\begin{tabular}{|c|c|c|c|c|c|}
\hline \multirow{3}{*}{ 10. Absence of contrast between $/ 1 /$ and $/ \mathrm{n} /$} & ML & 2.77 & 1.07 & & \multirow{3}{*}{$0.00 * *$} \\
\hline & $\mathrm{HK}$ & 3.36 & 1.11 & \multirow{2}{*}{3.26} & \\
\hline & ML & 2.24 & 1.22 & & \\
\hline \multirow{2}{*}{ 11. Absence of contrasts between voiced and voiceless sounds } & $\mathrm{HK}$ & 3.17 & 1.05 & \multirow{2}{*}{3.63} & \multirow{2}{*}{$0.00 * *$} \\
\hline & ML & 2 & 1.08 & & \\
\hline \multirow{2}{*}{ 12. Deletion of final /1/ } & HK & 3.48 & 1.12 & \multirow{2}{*}{2.58} & \multirow{2}{*}{$0.01 * *$} \\
\hline & ML & 2.64 & 1.14 & & \\
\hline \multirow{2}{*}{ 13. L-vocalization } & HK & 3.04 & 1.19 & \multirow{2}{*}{1.29} & \multirow{2}{*}{0.21} \\
\hline & ML & 2.57 & 1.25 & & \\
\hline \multirow{2}{*}{ 14. $/ \mathrm{r} /$ is pronounced as $/ 1 /$} & HK & 2.58 & 1.32 & \multirow{2}{*}{1.96} & \multirow{2}{*}{0.06} \\
\hline & ML & 1.83 & 1.1 & & \\
\hline \multirow{2}{*}{$15 . / \mathrm{r} /$ is pronounced as $/ \mathrm{w} /$} & HK & 2.92 & 1.04 & \multirow{2}{*}{3.55} & \multirow{2}{*}{$0.00 * *$} \\
\hline & ML & 1.76 & 1.03 & & \\
\hline \multirow{2}{*}{$16 . / \mathrm{v} /$ is pronounced as $/ \mathrm{f} /$} & HK & 3.43 & 1.16 & \multirow{2}{*}{2.69} & \multirow{2}{*}{$0.01 * *$} \\
\hline & ML & 2.41 & 1.23 & & \\
\hline \multirow{2}{*}{$17 . / \mathrm{v} /$ is pronounced as $/ \mathrm{w} /$} & HK & 3.04 & 1.16 & \multirow{2}{*}{-0.29} & 77 \\
\hline & ML & 3.14 & 1.04 & & 0.11 \\
\hline 18. $/ \mathrm{tr} /$ and $/ \mathrm{tw} /$ clusters are pronounced as $/ \mathrm{tSw} /$ & HK & 2.67 & 1.17 & 1.5 & 0.14 \\
\hline & HK & 2.09 & 1 & & \\
\hline 19. /S/ is pronounced as /s/ & ML & 1.89 & 1.02 & 0.63 & 0.54 \\
\hline 20 Incertion of consonant $/ \mathrm{t} / \mathrm{or} / \mathrm{s} /$ at the end & $\mathrm{HK}$ & 2.75 & 1.23 & 125 & 022 \\
\hline 20. insertion or consonant $/ \mathrm{t} /$ or $/ \mathrm{s} / \mathrm{at}$ the end & ML & 2.29 & 1.27 & 1.25 & 0.22 \\
\hline 21 Insertion of yowel /iv/ at the end of the words & HK & 2.7 & 1.11 & 217 & $004 * *$ \\
\hline 21. minsertion or vower fia/ at mie ena or tire words & ML & 1.95 & 1.15 & 2.11 & $0.04^{\prime}$ \\
\hline 22 Insertion of yowel / / in initial conconant clucters & HK & 2.04 & 0.93 & 242 & $002 * *$ \\
\hline 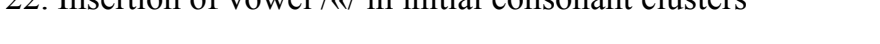 & ML & 2.84 & 1.21 & -2.42 & 0.02 \\
\hline 23 Inannronriate word stress & HK & 3.38 & 0.97 & 063 & 054 \\
\hline & ML & 3.14 & 1.49 & & \\
\hline 24 Inannropriate sentence stress & HK & 3.13 & 0.97 & -028 & 0.78 \\
\hline & ML & 3.23 & 1.34 & & \\
\hline 25. Syllable-timed rhythm & HK & 3.56 & 1.23 & 0.79 & 0.44 \\
\hline & ML & 3.27 & 1.28 & 0.19 & 0.44 \\
\hline 26 Absence of linking & HK & 3.12 & 1.24 & -03 & 076 \\
\hline 20. AUSCIICC OI IIIKIIIg & ML & 3.23 & 1.19 & $-0 . J$ & 0.10 \\
\hline 27 Ahsence of elicion & HK & 2.91 & 1 & 026 & 08 \\
\hline 27. AUSEIICE OI CIISIOUI & ML & 3 & 1.23 & -0.20 & 0.0 \\
\hline 28 Absence of acsimilation & HK & 3.04 & 1.04 & 027 & 070 \\
\hline 28. Aosence or assimilation & ML & 3.14 & 1.36 & 0.21 & 0.19 \\
\hline 20 Jnannronriate nauce & HK & 2.92 & 1.15 & 0.5 & 062 \\
\hline 29. Mliappiopniale pause & ML & 3.09 & 1.19 & $-0 . J$ & 0.02 \\
\hline 30 Inannronriate sneech rate & HK & 3.21 & 1.14 & 055 & 059 \\
\hline 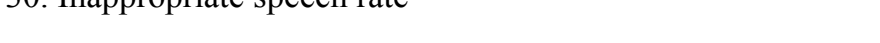 & ML & 3 & 1.41 & ( & 年 \\
\hline 31 Inannronriate intonation & HK & 2.92 & 0.93 & 03 & 077 \\
\hline 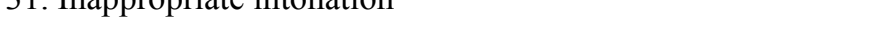 & ML & 2.82 & 1.3 & $0 . J$ & 0.11 \\
\hline Mean scores. & HK & 3.01 & 1.14 & 2 & $0.00 * *$ \\
\hline 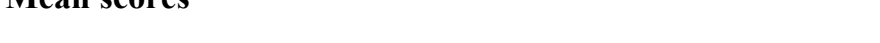 & ML & 2.58 & 1.18 & 2 & \\
\hline
\end{tabular}


Significant differences between the HK and ML groups were observed for items 4, 6, 7, 10-12, 15, 16, 21, and 22 when participants were asked about the pronunciation features that may impede intelligibility. Compared with Hong Kong teachers, whose mean score for all the 31 features was 3.01, ML teachers had a lower mean score (2.58), which suggests that ML teachers have less intelligibility problems with their students. However, it is worth noting that ML teachers gave a relatively higher score for suprasegmental features (from item 23 to item 31). It is reasonable to speculate that ML teachers deem suprasegmental features to be more vital to achieving intelligibility.

According to the interviews, all four teachers reported that they thought suprasegmental features (e.g. stress and rhythm pattern) may impede intelligibility in classroom communication.

HK-T1: I would pick word stress as the only severe pronunciation problem causing communication problems. I [have] some examples; when we talk about our RElatives, a lot of students will say reLAtive, and you may wonder what they are actually talking [about] in that case.

HK-T2: If we pronounce native English speakers' rhythm pattern, our students cannot understand. So we Chinese teachers always pronounce our speech word by word (word-level enunciation) to make sure that they can spell each word, so day after day, they cannot pronounce like native speakers.

ML-T1: I think stress is quite important. When you hear a word which is not correctly stressed, this will affect the intelligibility. I tend to stress the word and sentences and which part should be stressed and which part should be unstressed like "schwa."

ML-T2: Some features that are very common in my students, like "th" in thank you, but they do not cause any communication problem. Some inappropriate pausing and stress will impede the meaning. Regarding the specific sounds, the biggest problem is "v" and "w." Vowels are better than consonants in terms of the influence to intelligibility. Vowel problems do not influence communication much.

\subsubsection{Part 3. The Common Pronunciation Teaching Strategies}

Table 3 reveals that ML teachers apply more pronunciation teaching strategies than their HK counterparts. In the current data, the ML group applied the following ten pronunciation teaching strategies significantly more often than the HK group: "Choral repetition", "Minimal pair drills", "Pronunciation-focused recast", "Chanting", "Tongue twisters", "Language laboratory", "Video demonstration", "Imitation of native English", "Modelling the correct pronunciation", and "Using a chart with International Phonetic Alphabet (IPA) symbols".

In the ML group, the top three most frequently used pronunciation teaching strategies are "Modelling the correct pronunciation" ( $\mathrm{M}=4.50)$, "Choral repetition" $(\mathrm{M}=4.41)$, and "Reading aloud" $(\mathrm{M}=4.27)$, while the HK group marked "Breaking words into syllables" $(\mathrm{M}=4.08)$, "Modelling the correct pronunciation" $(\mathrm{M}=3.96)$, and "Reading aloud" $(\mathrm{M}=3.92)$ as the top three most frequently used pronunciation teaching strategies.

This result suggests that both ML and HK teachers deemed "Modelling the correct pronunciation" and "Reading aloud" as their most frequently used teaching strategies in their classrooms.

Table 3. Teachers' reflection on the common pronunciation teaching strategies

\begin{tabular}{|c|c|c|c|c|c|}
\hline & Group & $\mathrm{M}$ & SD & $\mathrm{t}$ & Sig.(2-tailed) \\
\hline \multirow{2}{*}{ 1. Choral repetition } & HK & 3.68 & 1.18 & \multirow{2}{*}{-2.40} & \multirow{2}{*}{$0.02 *$} \\
\hline & ML & 4.41 & 0.85 & & \\
\hline \multirow{2}{*}{ 2. Minimal pair drills } & HK & 2.84 & 1.03 & \multirow{2}{*}{-2.89} & \multirow{2}{*}{$0.01 *$} \\
\hline & ML & 3.73 & 1.08 & & \\
\hline \multirow{2}{*}{ 3.Pronunciation-focused recast } & HK & 3.26 & 0.92 & \multirow{2}{*}{-2.43} & \multirow{2}{*}{$0.02 *$} \\
\hline & ML & 3.95 & 1.00 & & \\
\hline \multirow{2}{*}{ 4. Back-chaining } & HK & 2.42 & 1.02 & \multirow{2}{*}{-1.48} & \multirow{2}{*}{0.15} \\
\hline & ML & 2.95 & 1.40 & & \\
\hline \multirow{2}{*}{ 5. Front-chaining } & HK & 2.92 & 1.25 & \multirow{2}{*}{-1.97} & \multirow{2}{*}{0.06} \\
\hline & ML & 3.59 & 1.05 & & \\
\hline \multirow{2}{*}{ 6.Chanting (usually like nursery rhyme with rhythm) } & HK & 2.58 & 1.32 & \multirow{2}{*}{-2.27} & \multirow{2}{*}{$0.03 *$} \\
\hline & ML & 3.41 & 1.14 & & \\
\hline 7.Reading aloud & HK & 3.92 & 1.00 & -1.28 & 0.21 \\
\hline
\end{tabular}




\begin{tabular}{|c|c|c|c|c|c|}
\hline & ML & 4.27 & 0.88 & & \multirow{3}{*}{$0.01 *$} \\
\hline \multirow{2}{*}{ 8.Tongue twisters } & $\mathrm{HK}$ & 2.40 & 0.91 & \multirow{2}{*}{-2.80} & \\
\hline & ML & 3.23 & 1.11 & & \\
\hline \multirow{2}{*}{ 9.English drama } & HK & 2.96 & 1.21 & \multirow{2}{*}{-0.24} & \multirow{2}{*}{0.81} \\
\hline & ML & 3.05 & 1.21 & & \\
\hline \multirow{2}{*}{ 10.Language laboratory } & HK & 2.63 & 1.35 & \multirow{2}{*}{-3.51} & \multirow{2}{*}{$0.00 * *$} \\
\hline & ML & 3.91 & 1.11 & & \\
\hline \multirow{2}{*}{ 11.Group work } & HK & 3.79 & 1.14 & \multirow{2}{*}{-0.50} & \multirow{2}{*}{0.62} \\
\hline & ML & 3.95 & 1.05 & & \\
\hline \multirow{2}{*}{ 12.Pair work } & HK & 3.72 & 0.98 & \multirow{2}{*}{-1.97} & \multirow{2}{*}{0.06} \\
\hline & ML & 4.23 & 0.75 & & \\
\hline \multirow{2}{*}{ 13.Role-play/Dialogue-acting } & HK & 3.44 & 1.19 & \multirow{2}{*}{-1.78} & \multirow{2}{*}{0.08} \\
\hline & ML & 4.00 & 0.93 & & \\
\hline \multirow{2}{*}{ 14.Video demonstration } & HK & 2.63 & 1.21 & \multirow{2}{*}{-3.48} & \multirow{2}{*}{$0.00 * *$} \\
\hline & ML & 3.76 & 0.94 & & \\
\hline \multirow{2}{*}{ 15.Imitation of native English } & HK & 3.21 & 1.18 & \multirow{2}{*}{-2.19} & \multirow{2}{*}{$0.03 *$} \\
\hline & ML & 3.91 & 0.97 & & \\
\hline \multirow{2}{*}{ 16.Modelling the correct pronunciation } & HK & 3.96 & 0.84 & \multirow{2}{*}{-2.32} & \multirow{2}{*}{$0.03 *$} \\
\hline & ML & 4.50 & 0.69 & & \\
\hline \multirow{2}{*}{ 17.Breaking words into syllables } & HK & 4.08 & 0.81 & \multirow{2}{*}{-0.64} & \multirow{2}{*}{0.52} \\
\hline & ML & 4.23 & 0.75 & & \\
\hline \multirow{2}{*}{ 18.Using a chart with IPA symbols } & HK & 1.79 & 1.06 & \multirow{2}{*}{-3.01} & \multirow{2}{*}{$0.00 * *$} \\
\hline & ML & 2.90 & 1.41 & & \\
\hline 19 Teaching pronunciation rules & HK & 2.76 & 1.27 & -206 & 005 \\
\hline 19. . & ML & 3.50 & 1.19 & -2.00 & 0.00 \\
\hline 20.Using hands, face \& real objects to teach segmental sounds, & HK & 2.96 & 1.14 & -1.14 & 026 \\
\hline stress and rhythm & ML & 3.36 & 1.29 & & \\
\hline
\end{tabular}

According to the interviews, however, the most common pronunciation teaching strategies reported by these four teachers were to some extent inconsistent with the results from the questionnaire. In addition to the strategies (e.g. choral repetition, model the pronunciation, group work, and pair work) having been reported in questionnaire, these four teachers claimed that they also used strategies like showing IPA symbols, phonics, videos demonstration, drama, and tongue twisters.

HK-T1: I will use choral repetition whenever I introduce new words. I usually show them the IPA symbols. For example, a few days ago, a student [had] difficulty in pronouncing the word "satisfaction". He inserted an extra syllable and pronounce[d] it like "satisfication", so I just show[ed] him [using] the IPA symbols that we only have four syllables, four vowels.

HK-T2: My school is using Primary Literacy Programme-Reading \& Writing (PLP-R/W). That is a program proposed by the Education Bureau (EdB). It requires us to teach kids with these kind[s of] phonetic skills. We are encouraged to use activities approach, like group work, pair work, role play, videos demonstration through [the] internet. Even during the lunch time, I can switch on the computer and [demonstrate] the video to them.

ML-T1: When I taught primary school students, we use[d] chanting a lot and drama. I use drama a lot [with] my senior primary school students; we learn one play every two weeks.

You teach them skills like "ph", show them the sound (model the pronunciation) and then relate it to the letters. [It is] just a little bit like phonics, [how] the sounds and the letters [are] related.

ML-T2: The most common strategies are choral repetition, pair work, group word, role play, but I found choral repetition, tongue twist, and chanting are most effective because my students are interested in this kind of practice. Sometimes I will also mention some rules to students in upper form, but for lower forms, I tend to use more interesting activities, like tongue twisters and group word and to avoid the pronunciation rules.

The cause of the inconsistence occurred between the result from the interview and the results from the 
questionnaire might be because these four teacher participants were recruited on a voluntary basis. They were the Master of Arts in Teaching English to Speakers of Other Languages (MATESOL) graduates taking the author's English phonology course years ago. They attempted to integrate phonics and phonetics knowledge learnt in this course into their daily teaching. They were also willing to experiment and try out innovative practice. HK-T2 further tested different pronunciation teaching strategies keenly learnt from the PLP-R/W literacy program provided by EdB in which reading and writing are taught holistically. These were evidenced that compared with the other 43 teacher participants in the survey, these four teachers were highly motivated teachers in their teaching career and active learners in their professional development. They used a wide variety of teaching strategies in their English classes.

\subsubsection{Part 4. The Aspects of Pronunciation that are Taught in Your Language Lesson}

Table 4 reveals that ML teachers teach the majority of the pronunciation components significantly more often than their Hong Kong counterparts. To be more specific, ML teachers teach the following twelve pronunciation aspects significantly more often than their Hong Kong counterparts: "phonetic alphabet (IPA)", "phonics knowledge", "voiced or voiceless", "syllable structure", "the pronunciation rules of past-tense marker "-ed", "the pronunciation rules of plural forms "-s", "word stress", "sentence stress", "stress-timed rhythm", "intonation", "pausing", and "linking".

In the HK group, the top four most frequently taught pronunciation aspects are "consonant clusters" $(\mathrm{M}=3.28)$, "word stress" $(M=3.24)$, "sentence stress" $(M=3.16)$, and "pausing" $(M=3.16)$, while the ML group marked "voiced or voiceless" $(M=3.95)$, "word stress" $(M=3.95)$, "intonation" $(M=3.86)$, and "sentence stress" $(M=3.82)$ as the top four most frequently taught pronunciation aspects. "Word stress" and "sentence stress" are two pronunciation aspects frequently taught by both ML and HK teachers.

Table 4. The aspects of pronunciation that are taught in your language lesson

\begin{tabular}{|c|c|c|c|c|c|}
\hline & Group & $\mathrm{M}$ & SD & $\mathrm{t}$ & Sig. (2-tailed) \\
\hline \multirow[t]{2}{*}{ 1. Phonetic alphabet (IPA) } & $\mathrm{HK}$ & 2.20 & 1.35 & \multirow{2}{*}{-2.97} & \multirow{2}{*}{$0.01 *$} \\
\hline & ML & 3.42 & 1.35 & & \\
\hline \multirow[t]{2}{*}{ 2. Phonics knowledge } & $\mathrm{HK}$ & 2.83 & 1.37 & \multirow{2}{*}{-2.44} & \multirow{2}{*}{$0.02 *$} \\
\hline & ML & 3.73 & 1.08 & & \\
\hline \multirow{2}{*}{ 3.Voiced or voiceless } & $\mathrm{HK}$ & 2.46 & 1.14 & \multirow{2}{*}{-4.81} & \multirow{2}{*}{$0.00 * *$} \\
\hline & ML & 3.95 & 0.95 & & \\
\hline \multirow[t]{2}{*}{ 4.Schwa/a/ } & $\mathrm{HK}$ & 2.58 & 1.02 & \multirow{2}{*}{-1.93} & \multirow{2}{*}{0.06} \\
\hline & ML & 3.22 & 1.11 & & \\
\hline \multirow[t]{2}{*}{ 5. Consonant clusters } & $\mathrm{HK}$ & 3.28 & 1.17 & \multirow{2}{*}{-0.53} & \multirow{2}{*}{0.60} \\
\hline & ML & 3.45 & 1.06 & & \\
\hline \multirow[t]{2}{*}{ 6. Allophones } & HK & 2.20 & 1.08 & \multirow{2}{*}{-1.53} & \multirow{2}{*}{0.13} \\
\hline & ML & 2.73 & 1.28 & & \\
\hline \multirow[t]{2}{*}{ 7. Syllable structure } & $\mathrm{HK}$ & 2.32 & 1.28 & \multirow{2}{*}{-2.73} & \multirow{2}{*}{$0.01 *$} \\
\hline & $\mathrm{ML}$ & 3.32 & 1.21 & & \\
\hline \multirow{2}{*}{$\begin{array}{l}\text { 8. The pronunciation rules of } \\
\text { past-tense marker '-ed' }\end{array}$} & $\mathrm{HK}$ & 2.84 & 1.21 & \multirow{2}{*}{-2.47} & \multirow{2}{*}{$0.02 *$} \\
\hline & ML & 3.73 & 1.24 & & \\
\hline \multirow{2}{*}{$\begin{array}{l}\text { 9. The pronunciation rules of plural } \\
\text { forms '-s' }\end{array}$} & HK & 2.84 & 1.28 & \multirow{2}{*}{-2.65} & \multirow{2}{*}{$0.01 *$} \\
\hline & ML & 3.77 & 1.11 & & \\
\hline \multirow[t]{2}{*}{ 10. Word stress } & HK & 3.24 & 1.13 & \multirow{2}{*}{-2.29} & \multirow{2}{*}{$0.03 *$} \\
\hline & ML & 3.95 & 1.00 & & \\
\hline \multirow[t]{2}{*}{ 11. Sentence stress } & $\mathrm{HK}$ & 3.16 & 1.14 & \multirow{2}{*}{-2.12} & \multirow{2}{*}{$0.04 *$} \\
\hline & ML & 3.82 & 0.96 & & \\
\hline 12. Stress-timed rhythm & HK & 2.40 & 1.12 & 308 & $0 \Omega 0 * *$ \\
\hline & ML & 3.32 & 0.89 & -5.00 & 0.00 \\
\hline 13.Intonation & $\mathrm{HK}$ & 3.12 & 1.05 & 266 & $001 *$ \\
\hline & ML & 3.86 & 0.83 & -2.00 & \\
\hline
\end{tabular}




\begin{tabular}{llllll}
\hline 14. Pausing & HK & 3.16 & 1.07 & -2.44 & $0.02 *$ \\
15. Linking & ML & 3.86 & 0.89 & & \\
\multirow{2}{*}{ 16. Assimilation } & HK & 2.60 & 0.91 & -3.22 & $0.00 * *$ \\
17. Elision & ML & 3.55 & 1.10 & & \\
& HK & 2.44 & 0.82 & -1.37 & 0.18 \\
& ML & 2.86 & 1.24 & & \\
& HK & 2.40 & 0.82 & -1.06 & 0.30 \\
\hline
\end{tabular}

According to the interviews, HK-T1 and ML-T1 focused more on suprasegmental features, like stress, when they taught pronunciation, while HK-T2 and ML-T2 focused more on segmental features, like the pronunciation of vowels and consonants. They have varying attitudes toward whether the teaching focus should be on segmental or suprasegmental features.

HK-T1: I think they are equally important, both segmental and suprasegmental, but it is more difficult to master the suprasegmentals. I will focus more on suprasegmental features.

HK-T2: I think vowels and consonants are basic units of sounds, so I think they are more important for students to learn. For lower-ability primary students, they can understand teachers by even a single word.

ML-T1: Yes, I taught them ("sentence stress", "word stress", and "stress-timed rhythm") almost every lesson. Yes, I think stress is quite important. When you hear a word which is not correctly stressed, this will affect the intelligibility.

ML-T2: We do not teach IPA symbols, we just demonstrate the sound of each letter but won't write the symbols for them. We mainly use phonics to teach the pronunciation of vowels and consonants.

\subsubsection{Part 5. Pronunciation Teaching Style and Belief}

Table 5 shows that both HK and ML teachers use a more "proactive approach" ( $40 \%$ for HK teachers and $45 \%$ for ML teachers) than "remedial approach" (20\% for HK teachers and $32 \%$ for ML teachers). "Intelligible pronunciation" was marked as a target of pronunciation teaching by $40 \%$ of HK teachers and $36 \%$ of ML teachers, whereas only $12 \%$ of $\mathrm{HK}$ teachers and $27 \%$ of ML teachers choose to target "native-like pronunciation".

More than $70 \%$ of the Hong Kong subjects indicated that they prefer to teach pronunciation in an integrated way, especially with listening and speaking practice, versus $55 \%$ of the ML subjects (as seen in item 6). In items 15 and $16,36 \%$ of ML and HK teachers prefer to teach pronunciation in "Mini lesson: little but more often" instead of "Whole lesson: more but less often" ( $8 \%$ of HK and 18\% of ML). It is noted that the HK teachers focus more on the segmental part $(44 \%)$ than the suprasegmental part $(24 \%)$, while ML teachers focus more on the suprasegmental parts $(50 \%)$ instead of the segmental parts (41\%).

Table 5. Teachers' pronunciation teaching style and belief

\begin{tabular}{lllll}
\hline No. & Item & HK & ML & Mean \\
\hline 1 & Proactive approach & $40 \%$ & $45 \%$ & $43 \%$ \\
2 & Remedial approach & $20 \%$ & $32 \%$ & $26 \%$ \\
3 & Explicit & $44 \%$ & $41 \%$ & $43 \%$ \\
4 & Incidental & $20 \%$ & $5 \%$ & $13 \%$ \\
5 & Separate lesson & $4 \%$ & $27 \%$ & $16 \%$ \\
6 & Integrated lesson & $72 \%$ & $55 \%$ & $64 \%$ \\
6.1 & listening & $28 \%$ & $18 \%$ & $23 \%$ \\
6.2 & speaking & $32 \%$ & $18 \%$ & $25 \%$ \\
6.3 & reading & $28 \%$ & $14 \%$ & $21 \%$ \\
6.3 & writing & $16 \%$ & $14 \%$ & $15 \%$ \\
6.4 & grammar & $12 \%$ & $14 \%$ & $13 \%$ \\
7 & Perception (listening) & $32 \%$ & $41 \%$ & $37 \%$ \\
\hline
\end{tabular}




\begin{tabular}{lllll}
\hline 8 & Production (speaking) & $60 \%$ & $64 \%$ & $62 \%$ \\
9 & Focus on fluency & $56 \%$ & $55 \%$ & $56 \%$ \\
10 & Focus on accuracy & $40 \%$ & $45 \%$ & $43 \%$ \\
11 & Target at Intelligibility & $40 \%$ & $36 \%$ & $38 \%$ \\
12 & Target at native-like pronunciation & $12 \%$ & $27 \%$ & $20 \%$ \\
13 & Focus on suprasegmental aspects & $24 \%$ & $50 \%$ & $37 \%$ \\
14 & Focus on segmental aspects & $44 \%$ & $41 \%$ & $43 \%$ \\
15 & Whole lesson: more but less often & $8 \%$ & $18 \%$ & $13 \%$ \\
16 & Mini lesson: little but more often & $36 \%$ & $36 \%$ & $36 \%$ \\
\hline
\end{tabular}

Finally, the open-ended question asked teachers about the changes in pronunciation teaching over their career. The six most frequently mentioned items are listed below:

1) From separate to integrated

2) Use more phonology and phonetics knowledge

3) Focus more on the mechanics of pronunciation

4) From a focus on accuracy to a focus on fluency

5) Changed to be more proactive

6) More involvement of phonics

The two most obvious changes reported by teachers were "from separate to integrated" and "more teaching instruments and strategies", which both had four mentions, including three from HK and one from ML for "from separate to integrated" and three from ML and one from HK for "more teaching instruments and strategies." Some examples are below.

From separate to integrated:

HK17: Pronunciation teaching can be integrated into reading, listening, or speaking activities where teachers can offer more frequent, immediate feedback to students' phonological skills.

ML8: I can infiltrate pronunciation teaching in the daily teaching.

Use more phonology and phonetics knowledge:

HK12: After learning the modules on them, I gradually become able to analyse the words into phonemes and teach the manners and places of articulation.

ML3: Use more phonics readers.

\subsection{Classroom Video Analyses}

Eight primary school teachers' videos, four from ML and four from HK, were collected and analysed. The results of the classroom observations shown in Table 6 indicate that the most common pronunciation-related adjustment strategies for both HK and ML teachers are "repetition", "speech rate modification", and "sentence stress emphasis". The results of the questionnaire in the previous section that are mainly based on teachers' self-reflection are generally consistent with what they actually do in the classroom.

The results of the classroom video analyses indicates that the most common pronunciation-related adjustment strategies for both HK and ML teachers are "repetition", "speech rate modification", and "sentence stress emphasis". This result is highly consistent with their responses in the questionnaire.

Regarding the main pronunciation teaching strategies that were spotted in the classroom observation, it was found that all eight teachers modelled the correct pronunciation for students when they taught unfamiliar words (e.g. "What's this? A suitcase, very good, a suitcase"). Six of the teachers employed choral repetition (e.g. "It's six fif'teen, Whole class, "fif'teen"), four teachers used "break words into syllables" (e.g. "hamburger" $\rightarrow$ "ham-bur-ger"), and only one teacher (HK4) used "phonics knowledge" (e.g. "remember the flati:/in peanut") and "chant" (e.g. teacher taught "recipe" by asking students to chant and clap their hands) when she taught the pronunciation of new words. 
Table 6. Result of classroom observation: pronunciation-related adjustment strategies

\begin{tabular}{|c|c|c|c|c|c|c|c|c|}
\hline $\begin{array}{l}\text { Strategy } \\
\text { Teacher }\end{array}$ & $\begin{array}{l}\text { S1. } \\
\text { SRM }\end{array}$ & $\begin{array}{l}\text { S2. } \\
\text { WE }\end{array}$ & $\begin{array}{l}\text { S3. } \\
\text { IE }\end{array}$ & $\begin{array}{l}\text { S4. } \\
\text { SSE }\end{array}$ & $\begin{array}{l}\text { S5. } \\
\text { REP }\end{array}$ & $\begin{array}{l}\text { S6. } \\
\text { RM }\end{array}$ & $\begin{array}{l}\text { S7. } \\
\text { SLE }\end{array}$ & $\begin{array}{l}\text { Lesson duration } \\
\text { (mins) }\end{array}$ \\
\hline HK1 & 8 & 3 & 4 & 7 & 8 & 8 & 0 & 30 \\
\hline HK2 & 6 & 3 & 4 & 5 & 7 & 3 & 0 & 59 \\
\hline HK3 & 3 & 4 & 5 & 5 & 4 & 3 & 0 & 31 \\
\hline HK4 & 2 & 1 & 3 & 2 & 1 & 0 & 0 & 37 \\
\hline Total & 19 & 11 & 16 & 19 & 20 & 14 & 0 & 157 \\
\hline ML1 & 3 & 1 & 1 & 2 & 3 & 2 & 4 & 43 \\
\hline ML2 & 4 & 1 & 5 & 3 & 5 & 2 & 0 & 45 \\
\hline ML3 & 1 & 0 & 0 & 0 & 1 & 1 & 1 & 60 \\
\hline ML4 & 2 & 5 & 2 & 4 & 0 & 2 & 0 & 44 \\
\hline Total & 10 & 7 & 8 & 9 & 9 & 7 & 5 & 192 \\
\hline
\end{tabular}

Note.

1. The number in this table means the frequency one strategy being used in classroom.

2. S1.SRM. = Speech rate modification; S2. WE=Word-level enunciation; S3.IE= Intonation emphasis; S4.SSE= Sentence stress emphasis; S5. REP=Repetition; S6. FM=Fluency modification; S7.SLE= Segmental-level enunciation.

Table 7. Result of classroom observation: Pronunciation teaching strategies

\begin{tabular}{|c|c|c|c|c|c|c|}
\hline $\begin{array}{l}\text { Strategy } \\
\text { Teacher }\end{array}$ & $\begin{array}{l}\text { S1. } \\
\text { MC }\end{array}$ & $\begin{array}{l}\text { S2. } \\
\text { CR }\end{array}$ & $\begin{array}{l}\text { S3. } \\
\text { BWS }\end{array}$ & $\begin{array}{l}\text { S4. } \\
\text { PK }\end{array}$ & $\begin{array}{l}\text { S5. } \\
\text { CT }\end{array}$ & $\begin{array}{l}\text { Lesson duration } \\
\text { (mins) }\end{array}$ \\
\hline HK1 & 1 & & & & & 30 \\
\hline HK2 & 3 & 4 & & & & 59 \\
\hline HK3 & 1 & 1 & 1 & & & 31 \\
\hline HK4 & 3 & 3 & 2 & 1 & 1 & 37 \\
\hline Total & 8 & 8 & 3 & 1 & 1 & 157 \\
\hline ML1 & 3 & 2 & 2 & & & 43 \\
\hline ML2 & 1 & 1 & 2 & & & 45 \\
\hline ML3 & 1 & & & & & 60 \\
\hline ML4 & 3 & 3 & & & & 44 \\
\hline Total & 8 & 6 & 4 & 0 & 0 & 192 \\
\hline
\end{tabular}

1. The number in this table means the frequency one strategy being used in classroom.

2. $S 1 . M C=$ Model the correct pronunciation; S2. $C R=$ Choral repetition; S3.BWS= Breaking words into syllables; $S 4 . P K=$.Phonics knowledge"; S5. CT=Chant.

Some examples of repetition, speech rate modification, sentence emphasis, word-level enunciation, segmental-level enunciation, intonation emphasis, and fluency modification transcribed from the videos are illustrated below:

1) Repetition

e.g. "You have fifteen seconds, only fifteen seconds, remember". (HK1)

e.g. “And this part read as narrator, narrator, understand?" (ML3)

2) Speech rate modification

e.g. (slow rate) "Remember---they---are---different". (HK1) 
e.g. (slow rate) "You---have---to decide---five things---you are going to bring with you". (HK1)

3) Sentence stress emphasis

e.g. "REMEMBER. They are DIFFERENT". (HK1)

e.g. "All of these are VEHICLES". (ML4)

4) Word-level enunciation

e.g. "She gets up at 7 o'clock in the morning. Get or gets?" (HK2)

e.g. "It also tells you that you have to be a good student, you should read books, remember". (HK3)

5) Segmental-level enunciation

e.g. "Play the pi-a-no". (ML1)

e.g. "Play the vi-o-lin". (ML1)

6) Intonation emphasis

e.g. "The place $\nearrow$, the person $\nearrow$, and what else?" (HK1)

e.g. "Can you write down your poem $\nearrow$ and read aloud $\nearrow$ ?" (ML1)

7) Fluency modification

e.g. "You can borrow---ok---borrow from me". (HK1)

e.g. "We can...? Well, Mm...we can...book the tickets on [the] internet". (ML4)

\section{Discussion and Conclusion}

This study examined pronunciation adjustment strategies and intelligibility in ESL /EFL Chinese classrooms in HK and ML. The ways in which teachers modify and adapt to make classroom discourse intelligible to students were found. The pronunciation aspects vital for intelligible pronunciation in actual English Classrooms in HK and ML were identified. The most frequently taught pronunciation aspects and the most frequently used pronunciation teaching strategies used in English classrooms were explored. In the following section, three related issues will be discussed: pronunciation adjustment strategies, pronunciation learning and intelligibility, and pronunciation teaching in $\mathrm{L} 2$ teacher education.

\subsection{Pronunciation Adjustment Strategies}

The questionnaire results indicate that the three most frequently used adjustment strategies of English teachers in ML are "repetition", "speech rate modification", and "segmental-level enunciation", while for English teachers in HK, the top three most frequently used adjustment strategies are "contraction avoidance", "sentence stress emphasis", and "repetition". It is obvious that ML teachers use the majority of the adaptation strategies significantly more often than their HK counterparts. The possible reasons would be because ML teachers received more professional trainings and had stronger teaching beliefs in focusing on both segmental and suprasegmental aspects of teaching. The details will be further elaborated in section 4.3 . The results in this study also echo Saito and van Poeteren (2012); the teachers reported using pronunciation-related adjustment strategies (e.g. speech rate modification, word-level enunciation, segmental-level enunciation) to modify their pronunciation in the classroom. This study is also consistent with Chaudron (1988) in the following aspects: 1) the rate of teacher talk speed is obviously slower than the natural talk speed. 2) More and longer pauses happen between utterances. 3) Pronunciation tends to be clearer, exaggerated, and with a higher and wider pitch range. More stresses are used and rhythm is obvious and clear. The contracted form of language is used less. 4) Basic and simple words are used often. 5) There is more self-repeat.

The teachers revealed in the interviews that they believe they have no communication problems with students because students can undertand teachers' speech via their speech rate modification; teachers can also guess students' meanings from the context even if students have made pronunciation errors. Both teachers' and students' accented speech in real classroom do not contain very complicated structures or words to present ideas. They usually use very short speech, repetitve phrases, simple words, or even one word to communicate to each other in English. However, as we know, teacher talk should be one of the most important inputs for primary school students in their daily life. Primary school teachers should be the model for students to imitate, and any pronunciation adjustments should be made with special care. Any language activities in class are for learning; therefore, simplified or unauthentic pronunciation adjustment, for example, overly slowing down the speech rate, intentionally ignoring the stressed rhythm patterns or oddly repeating phrases in these activities may lack real communicative information and, even worse, deprive students from learning good pronunciation. It is suggested 
that some consolidating or clarification tasks with quality input should be followed up in class or outside the class.

\subsection{Pronunciation Learning and Intelligibility}

Part 2 of the questionnaire was aimed at investigating the pronunciation features of students that may impede intelligibility in classrooms. Teachers' responses in this part reveal that the features compiled by the author are quite common amongst students in both ML and HK. Regarding the extent to which the features impede intelligibility, most of the teachers did not think the features impede the intelligibility in the classroom very much because they have become very familiar with their students' accents. The top three features HK teachers think will impede intelligibility most are "voiced th / $/$ / is pronounced as $/ \mathrm{d} /$ ", "syllable-timed rhythm", and "deletion of final /1/", while ML teachers named the top three as "syllable-timed rhythm", "inappropriate sentence stress", and "absence of linking". Compared to HK teachers, whose mean score for all the 31 features was 3.01, ML teachers had a lower mean score of 2.58, which suggests that ML teachers have less intelligibility problems with their students. However, it is worth noting that ML teachers gave a higher score for suprasegmental features (e.g. syllable-timed rhythm, word and sentence stress) than to segmental features. It is reasonable to speculate that ML teachers deem suprasegmental features to be more vital to achieving intelligibility.

The teachers' responses reveal that ESL/EFL students don't usually produce long and complicated sentences, and teachers usually inattentively correct their students' pronunciation when the deviation of pronunciation occurs. Most of the words and speeches students produced are based on the textbooks or the materials they just learnt, so teachers know the new items that they learn and they talk about. As Jenkin (2002) mentioned, the vast majority of English teaching takes place in the same L1 classrooms in the learners' own countries. When speakers come from the same L1 background, convergence for communicative efficiency and solidarity will result in an increase of phonological transfer, allowing and encouraging fossilization and use of deviant L2 forms in order to facilitate interlocutor intelligibility as well as to signal shared group identity. The teachers in this study have become very familiar with their students' English accents. As an ML teacher said, "Maybe at the beginning of my teaching I will feel a little bit strange about their pronunciation features, but after a few years, my ears have been adapted to their pronunciation problem. I can almost understand the majority of my students' speech". Rather than eliminating students' foreign accents, teachers as listeners, playing a more active role, have used their adjustment strategies to accommodate the accented speech. But is it good for Chinese ESL/EFL learners to learn pronunciation in this way? If they were placed in a multilingual classroom, could they manage to survive in that environment? Can they be successful in a real NNS versus NNS communication outside the classroom? All these need further investigation.

\subsection{Pronunciation Teaching in L2 Teacher Education}

Part 3 of the questionnaire investigated the most frequently used teaching strategies in HK and ML classroom settings. The result reveals that ML teachers in an EFL context know and apply significantly more pronunciation teaching strategies to improve students' pronunciation than their HK counterparts in an ESL context. But, both ML and HK teachers deemed "modelling the correct pronunciation" and "reading aloud" as the most frequently used teaching strategies in their classrooms.

Two possible reasons can explain this phenomenon. First, these two techniques are less time consuming and easy to apply in a larger class. As one HK teacher said, "Different students make different mistakes, and teachers cannot correct them all. In particular, pronunciation is not separately assessed, so there is no sufficient time to allocate it". Second, both teachers and students lack knowledge of English phonetics and phonology. The two most frequently used techniques involve less phonological knowledge or terminology. Most HK teachers are not familiar with the English phonetic system and do not feel confident using explicit phonological rules to teach pronunciation for senior primary students. Even ML teachers and students know better and more about phonological knowledge, and as one ML teacher pessimistically mentioned, "Students are not able to understand phonics or phonetic symbols. It is no use to teach pronunciation in that way".

Part 4 of the questionnaire investigated the most frequently taught pronunciation aspects in $\mathrm{HK}$ and ML classroom settings. Regarding the pronunciation aspects taught in classrooms, ML teachers in the EFL context teach the majority of the pronunciation components significantly more often than their HK counterparts in the ESL context. Compared with learners in the ESL context, ML learners in the EFL context, to use Kachru's (1982) term, are "norm-dependent" because they rely more on the standards set by native English speakers. Even though EFL learners' speech is intelligible enough for the listeners, most English teachers still use Received 
Pronunciation (RP) or the General American (GA) pronunciation as the standard to improve their students' oral English.

Among all the pronunciation components, "word stress" and "sentence stress" are the two most frequently taught pronunciation aspects by both ML and HK teachers, but by mostly using "modelling the correct pronunciation" and "reading aloud" strategies. In Baker's (2011) interview study, she revealed that teachers whose TESOL training included a course in pronunciation pedagogy reported prioritizing the teaching of suprasegmental features of pronunciation in their classes. At the same time, however, many of these teachers still seemed to lack confidence in teaching some components of English pronunciation. It sheds some light on the English teacher education program that the different aspects of phonological content knowledge, as well as the pronunciation pedagogical skills, should be strengthened.

\section{4 Limitations and Further Studies}

This is a pioneering study exploring how Chinese primary teachers use different pronunciation modification strategies to make their lessons intelligible to their primary Chinese students and how English pronunciation components are taught in their English classes. However, this study only focused on the interactions between teachers and students who shared a first language, either Mandarin or Cantonese.

Hong Kong is a multilingual society, so NNS versus NNS communication in English is commonly observed in ESL classrooms (e.g. Cantonese students versus south Asian teachers/mainland teachers or Mandarin students versus Cantonese teachers in English as a medium of instruction). Further studies could consider pronunciation teaching and modification strategies by comparing teachers from varying linguistic backgrounds, such as Hong Kong (L1 is Cantonese), mainland China (L1 is Mandarin), the Philippines (L1 is Tagalog), or Pakistan (L1 is Pakistani). It would be of great value to determine whether and in what ways English teachers with various mother tongues/dialects tackle English pronunciation teaching/modification strategies. Such studies would benefit Chinese and non-Chinese ESL teachers in Hong Kong by increasing their sensitivity to the use of different pronunciation teaching/modification strategies with Chinese learners of English with different dialects and learning backgrounds. If the goal of reducing an L2 speakers' accent is less achievable, the L2 listeners could take a more active role. Interlanguage speaking practice is helpful at the receptive level by providing learners with exposure to a range of English as an international language accents other than their own (Jenkin, 2002). Remedial strategies of pronunciation for Chinese speakers and accommodation strategies for listeners from other language backgrounds could then be suggested. It is also interesting to propose trainings for the listeners to comprehend accented speech in EFL/ESL or different dialect environments. Finally, students' perceived effectiveness of the teaching strategies discussed in this paper would be another worth investigating topic for future studies.

\section{References}

Baker, A. A. (2011). Discourse prosody and teachers' stated beliefs and practices. TESOL Journal, 2, 263-292. http://dx.doi.org/10.5054/tj.2011.259955

Breitkreutz, J., Derwing, T. M., \& Rossiter, M. J. (2001). Pronunciation teaching practices in Canada. TESL Canada Journal, 19, 51-61.

Burgess, J., \& Spencer, S. (2000). Phonology and Pronunciation in Integrated Language Teaching and Teacher Education. System, 28(2), 191-215. http://dx.doi.org/10.1016/S0346-251X(00)00007-5

Chaudron, C. (1988). Second Language Classrooms: Research on Teaching and Learning. Cambridge: Cambridge University Press. http://dx.doi.org/10.1017/CBO9781139524469

Cheung, H. (1999). Improving phonological awareness and word reading in a later learned alphabetic script. Cognition, 70, 1-26. http://dx.doi.org/10.1016/S0010-0277(98)00074-2

Chen, H. C., Chan, W. P. M., Chan, K. Y., Chee, E., \& Wang, L. (2014). The Spoken Corpus of the English of Hong Kong and Mainland Chinese learners. Retrieved from http://ec-concord.ied.edu.hk/English_pronunciation/

Derwing, T. M., \& Munro, M. J. (2005). Second Language Accent and Pronunciation Teaching: A Research-Based Approach. TESOL Quarterly, 39(3), 379-397. http://dx.doi.org/10.2307/3588486

Derwing, T. M., Munro, M. J., \& Wiebe, G. (1997). Pronunciation instruction for fossilized learners: Can it help? Applied Language Learning, 8(2), 217-35.

Derwing, T. M., Munro, M. J., \& Wiebe, G. (1998). Evidence in favor of a broad framework for pronunciation instruction. Language Learning, 48(3), 393-410. http://dx.doi.org/10.1111/0023-8333.00047 
Fernald, A., \& Kuhl, P. (1987). Acoustic determinants of infant preference for motherese speech. Infant Behavior and Development, 10, 279-293. http://dx.doi.org/10.1016/0163-6383(87)90017-8

Field, J. (2005). Intelligibility and the listener: The role of lexical stress. TESOL Quarterly, 39, 399-423. http://dx.doi.org/10.2307/3588487

Jenkins, J. (2000). The phonology of English as an international language. Oxford: Oxford University Press.

Jenkins, J. (2002). A sociolinguistically based, empirically researched pronunciation syllabus for English as an international language. Applied Linguistics, 23, 83-103. http://dx.doi.org/10.1093/applin/23.1.83

Jenkins, J. (2005). Implementing an international approach to English pronunciation: The role of teacher attitudes and identity. TESOL Quarterly, 39, 535-543. http://dx.doi.org/10.2307/3588493

Kachru, B. B. (1982). Models for non-native Englishes. ELT Journal, 5(2), 119-126.

Levis, J. (2005). Changing contexts and shifting paradigms in pronunciation teaching. TESOL Quarterly, 39, 367-377. http://dx.doi.org/10.2307/3588485

Munro, M. J., \& Derwing, T. (1999). Foreign accent, comprehensibility, and intelligibility in the speech of second language learners. Language Learning, 49(Suppl. 1), 285-310. http://dx.doi.org/10.1111/0023-8333.49.s1.8

Murphy, J. M. (1997). Phonology courses offered by MATESOL programs in the U.S. TESOL Quarterly, 31(4), 741-764. http://dx.doi.org/10.2307/3587758

Piske, T., MacKay, I., \& Flege, J. (2001). Factors affecting degree of foreign accent in an L2: A review. Journal of Phonetics, 29, 191-215. http://dx.doi.org/10.1006/jpho.2001.0134

Read, C., Zhang, Y.-F., Nie, H.-Y., \& Ding, B.-Q. (1986). The ability to manipulate speech sounds depends on knowing alphabetic writing. Cognition, 24, 31-44. http://dx.doi.org/10.1016/0010-0277(86)90003-X

Ross, L. (1992). Teaching Phonology to teachers: the phonology element in initial training courses. In A. Brown (Ed.), Approaches to Pronunciation Teaching. Review of English Language Teaching, 2(2), 18-28, Macmillan, London.

Saito, K., \& Van Poeteren, K. (2012). Adjustment strategies for intelligibility in L2 teacher talk: Results and implications of a questionnaire study. Language Awareness, 21(4), 369-385. http://dx.doi.org/10.1080/09658416.2011.643891

Saito, K., \& Lyster, R. (2012). Effects of form-focused instruction and corrective feedback on L2 pronunciation development of $/ \mathbf{l} /$ by Japanese learners of English, Language Learning, 62(2), 595-633. http://dx.doi.org/10.1111/j.1467-9922.2011.00639.x

Setter, J., \& Jenkins, J. (2005). Pronunciation. Language Teaching, 38, 1-17. http://dx.doi.org/10.1017/S026144480500251X

Yule, G. (2010). The study of language (4th ed.) UK: Cambridge University Press. http://dx.doi.org/10.1017/CBO9780511757754

\section{Appendix I. Questionnaire}

\section{Intelligibility and pronunciation adjustment strategies in L2 classroom}

Dear Teachers,

You are invited to participate in our research project "Intelligibility and pronunciation adjustment strategies in English classrooms" This project aims to

$>\quad$ investigate the features that are important for intelligible communication in actual English classroom and how teachers help their students successfully understand English classroom input.

$>$ explore the most frequently-taught aspects of English pronunciation and how teachers teach them.

Your participation in this study is completely voluntary. Your personal information and survey responses will be strictly confidential. You have every right to withdraw from the study at any time without penalty of any kind.

If you have any questions regarding the project, please do not hesitate to contact us by email xxx 


\section{Personal information (Please " $\checkmark$ " the box as appropriate)}

1. Years of English teaching: years

2. Have you received any phonetics and phonology (P\&P) training or attended any P\&P courses?

$\checkmark$ Yes $\square$ No If yes, how long?

3. Your qualifications: $\square$ Bachelor of Arts $\square$ Bachelor of Education $\square$ Master of Arts $\square$ Master of Education $\square$ Doctor of Philosophy $\square$ Doctor of Education Others

4. Your target students: $\square$ Lower Primary $\square$ Upper Primary

5. Proficiency level of your students: $\quad$ low $\square$ intermediate $\square$ advanced

6. District/City of your school:

\section{Part 1. The most common pronunciation-related adjustment strategies}

Instructions: Do you modify your English consciously or unconsciously when you speak with your students to make them understand you better? If so, please indicate what pronunciation-related adjustment strategies you use and how often you use them. Don't know $=\mathrm{DK}(0)$, Never use $=(1)$, Seldom use $=(2)$ Sometimes use $=(3)$, Often $\underline{\text { use }=(4), \text { Always uses }=(5)}$

\begin{tabular}{|c|c|c|c|c|c|c|}
\hline & DK & & er- & ---- & Al & ays \\
\hline & 0 & 1 & 2 & 3 & 4 & 5 \\
\hline $\begin{array}{l}\text { 1. Speech rate modification } \\
\text { i.e. Teachers use relatively slow speech to help students understand their speech } \\
\text { better.e.g. (slow rate) Remember.---They---are---different. }\end{array}$ & & & & & & \\
\hline $\begin{array}{l}\text { 2. Word-level enunciation } \\
\text { i.e. Teachers' clear pronunciation of certain WORDS instead of exaggerating } \\
\text { individual sounds. } \\
\text { e.g. Teacher says "it also tells you that you have to be a GOOD STDUENT, you } \\
\text { should READ BOOKS, remember!" }\end{array}$ & & & & & & \\
\hline $\begin{array}{l}\text { 3. Segmental-level enunciation } \\
\text { i.e. Teachers' exaggerated enunciation of certain consonants and vowels. e.g. } \\
\text { Teachers teach pronunciation of "peanut" by saying pea---nut (stressing the long } \\
\text { vowel 'ea'/i:/) }\end{array}$ & & & & & & \\
\hline $\begin{array}{l}\text { 4. Contraction avoidance（避免縮略式） } \\
\text { i.e. Teachers intentionally avoid using contractions. } \\
\text { e.g. Teachers avoid using 'gonna'for 'going to' and 'wanna'for 'want to' }\end{array}$ & & & & & & \\
\hline $\begin{array}{l}\text { 5.Assimilation(同化), elision (省音), linking (連讀) avoidance } \\
\text { i.e. Teachers intentionally avoid assimilation (e.g. 'in that box' } \rightarrow \text { 'in thap box'), } \\
\text { elision (e.g. 'next day' } \rightarrow \text { 'nex day' /neksde/) and linking (e.g. 'a lot of' } \rightarrow \\
\text { 'a-lo-tof') }\end{array}$ & & & & & & \\
\hline $\begin{array}{l}\text { 6. Fluency modification } \\
\text { i.e. Teachers insert more pauses or repetitions in their classroom discourse. } \\
\text { e.g. Teachers' instruction: 'two members (pause) will do the action(pause), will do } \\
\text { the action' }\end{array}$ & & & & & & \\
\hline $\begin{array}{l}\text { 7. Intonation emphasis } \\
\text { i.e. Teachers highlight the English intonation patterns to draw students' attention. } \\
\text { e.g. Teachers' guiding question like "So } \nearrow \text { what you need to do is } \nearrow \text { ", }\end{array}$ & & & & & & \\
\hline $\begin{array}{l}\text { 8. Sentence stress emphasis } \\
\text { i.e. Teachers stress important information in a sentence }\end{array}$ & & & & & & \\
\hline
\end{tabular}




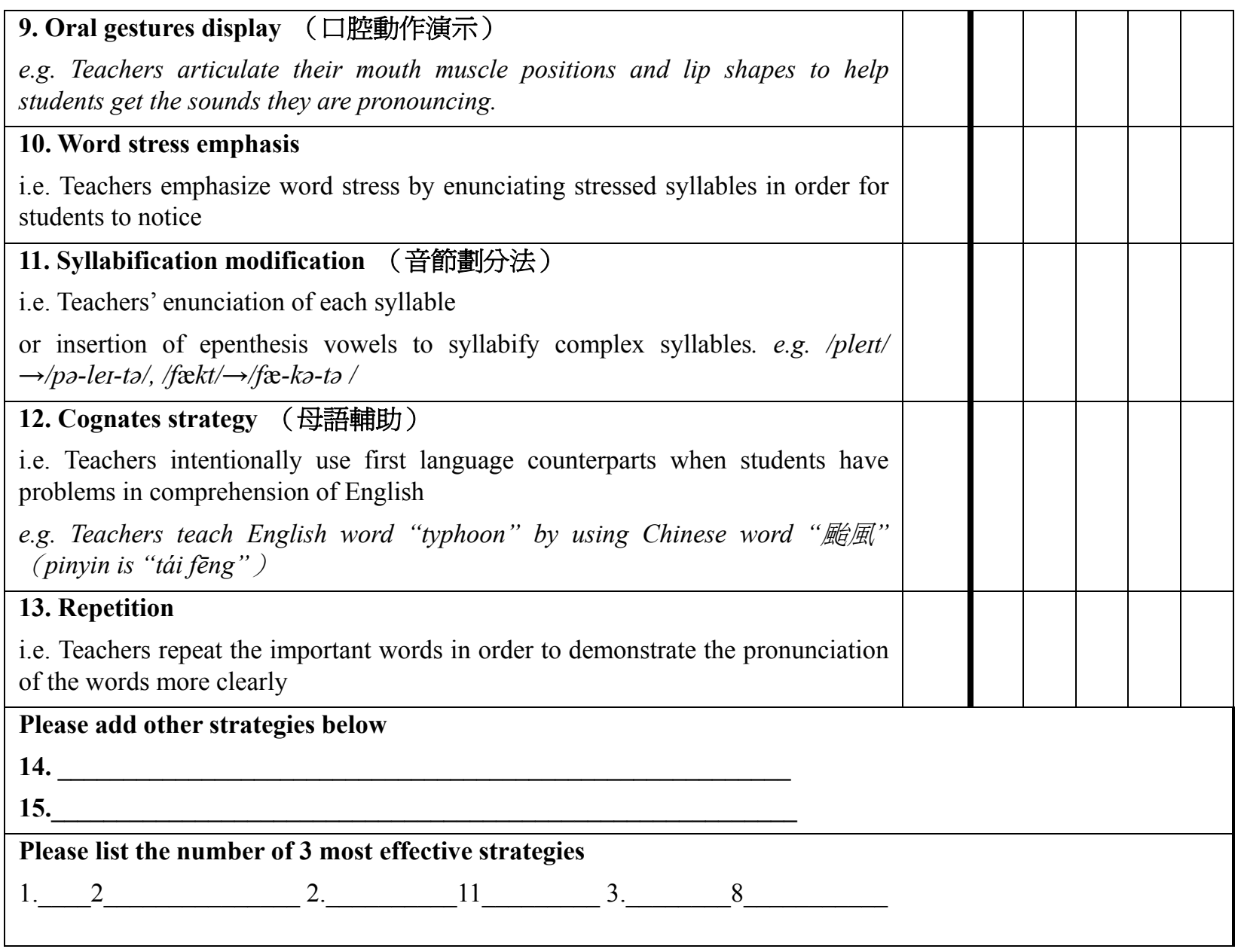

Part 2. The pronunciation features of your students that may impede the intelligibility in classrooms Instructions: Please indicate whether you students have the following listed pronunciation features, and how often they impede the intelligibility between you and your students. Please tick 'DK' if you do not know the feature(s); please tick 'No', if you students do not have the feature(s); please indicate the frequency of the features among your students if they have by clicking the frequency (1-5)

Don't know=DK (x), NO=(0), Never $=(1)$, Seldom $=(2)$ Sometimes $=(3)$, Often $=(4)$, Always $=(5)$

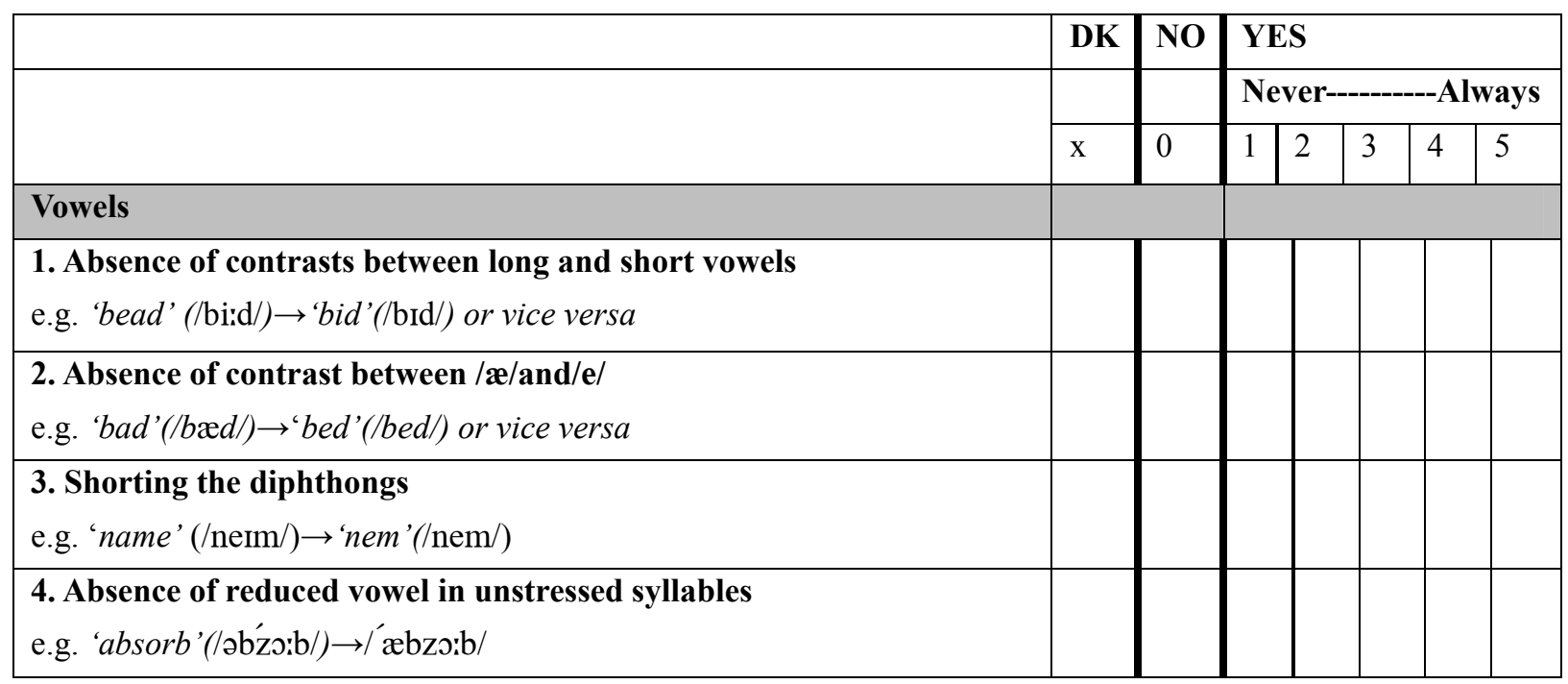




\section{Consonants}

5. Voiced TH/ð/ is pronounced as/z/

e.g. 'this' (/ ðıs/) $\rightarrow$ 'zis'(/zis/)

6. Voiced $T H / ð /$ is pronounced as/d/

e.g. 'those'(/ðəuz/) $\rightarrow$ 'dose'/dous/

7. Voiceless $\mathbf{T H} / \boldsymbol{\theta} /$ is pronounced as/f/

e.g. 'thanks' $(/ \theta æ j \mathrm{ks} /) \rightarrow$ 'fanks' $(/$ fæjks/)

8. Voiceless $\mathrm{TH} / \boldsymbol{\theta} /$ is pronounced as /t/

e.g. 'thin' $(/ \theta \mathrm{in} /) \rightarrow$ 'tin' $(/ \mathrm{tm} /)$

9. Voiceless $\mathrm{TH} / \boldsymbol{\theta} /$ is pronounced as /s/

e.g. 'think' $(/ \theta \mathrm{ink} /) \rightarrow$ 'sink'(/sink/)

10. Absence of contrast between $/ \mathbf{l} /$ and $/ \mathbf{n} /$

e.g. 'light' (/lart/) $\rightarrow$ 'night'(/nart/) or vice versa

\section{Absence of contrasts between voiced and voiceless sounds}

e.g. 'seal' (/si:1/) $\rightarrow$ 'zeal' (/zill/) or vice versa

\section{Deletion of final $/ \mathrm{l} /$}

e.g. fool(/fu:l/)' $\rightarrow$ 'foo'(/fu:/)

\section{L-vocalization （///元音化）}

L-vocalization refers to the realization of $/ 1 /$ as vowels like $/ \mathrm{u} /$ when it is preceded by a back vowel.

e.g. 'fool' (/fu:l/) $\rightarrow$ 'foo-o' (/ furd/)

14. $/ \mathbf{r} /$ is pronounced as $/ \mathbf{l} /$

e.g. 'right'(/ratt/) $\rightarrow$ 'light'(/lart/)

15. $/ \mathbf{r} /$ is pronounced as $/ \mathrm{w} /$

e.g. 'rice'(/rais/) $\rightarrow$ 'wise' (/wais/)

16. $/ \mathbf{v} /$ is pronounced as $/ \mathbf{f} /$

e.g. 'even'(/i:vn/) $\rightarrow$ 'efen' (/'i:fn/)

$17 . / \mathrm{v} /$ is pronounced as $/ \mathrm{w} /$

e.g. 'vine'(/vain/) $\rightarrow$ 'wine' (/waIn/),

18. $/ \mathbf{t r} /$ and $/ \mathbf{t w} /$ clusters are pronounced as $/ \mathbf{t} \mathbf{w} \mathbf{w}$

e.g. 'trim' $\left(/\right.$ trim/) $\rightarrow$ 'chwim' $\left(/ \mathrm{t} \int \mathrm{wIm} /\right)$

e.g. 'twin' $(/ \mathrm{twin} /) \rightarrow$ 'chwin' $\left(/ \mathrm{t} \int \mathrm{win} /\right)$

\section{$19 . / \mathbf{J} /$ is pronounced as $/ \mathbf{s} /$}

e.g. 'she'(//ii/) $\rightarrow$ 'see' (/si:/)

\section{Syllable structures}

\section{Insertion of consonant $/ \mathrm{t} / \mathrm{or} / \mathrm{s} /$ at the end}

e.g. 'option' $\rightarrow$ 'options' (/ppSns/)

21. Insertion of vowel $/ i$ / at the end of the words

e.g. 'miss' $\rightarrow$ 'missi'(/misi:/), 'tips' $\rightarrow$ 'tipsi' (/trpsi//)

\section{Insertion of vowel/o/ in initial consonant clusters}

e.g. 'place' $\rightarrow$ 'palace'((poleIs/) 


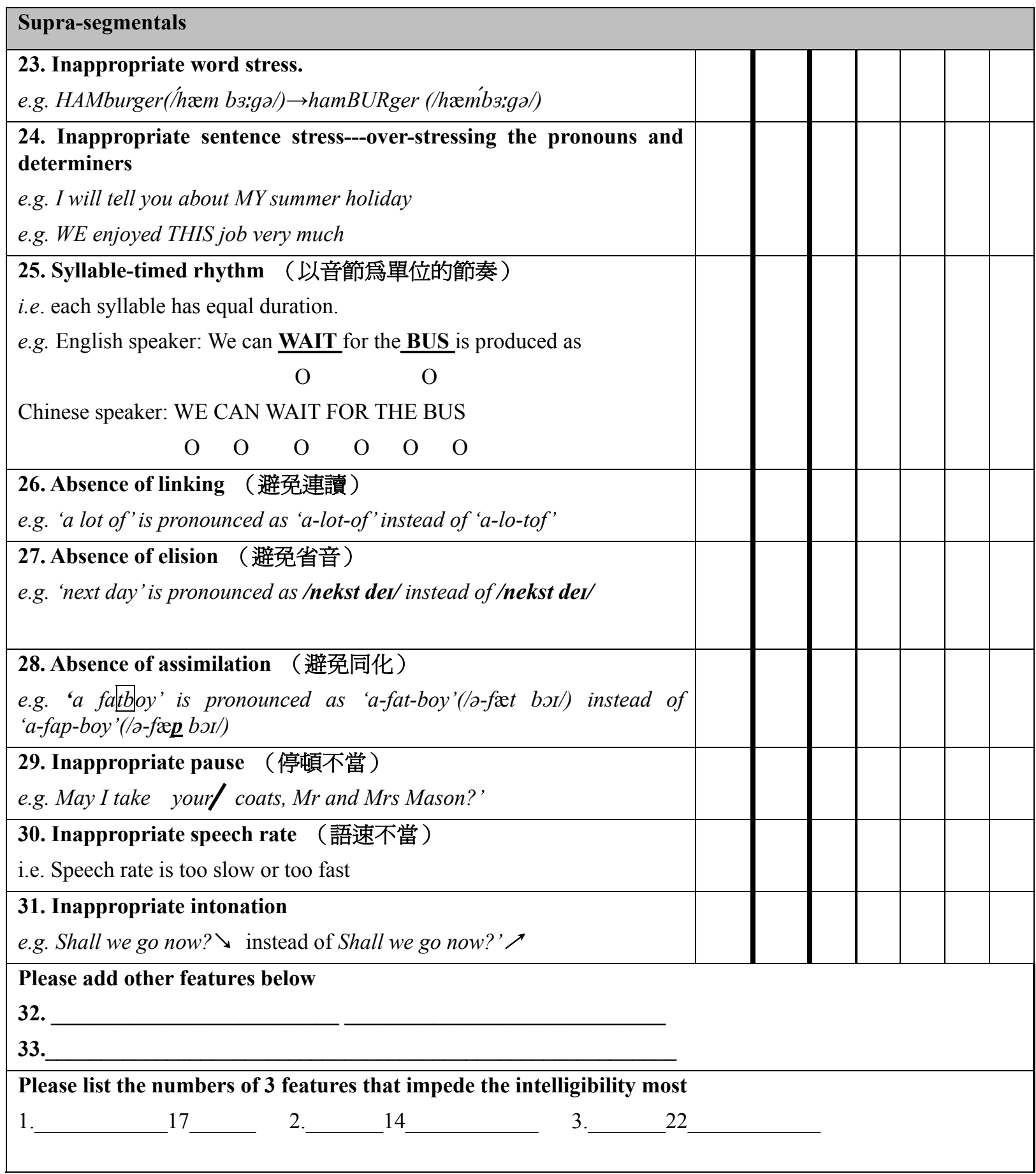

Part 3. The common pronunciation teaching strategies

Instructions: Please indicate what strategies you use and how often you use them in your teaching of pronunciation?

\begin{tabular}{|l|l|l|l|l|l|l|}
\hline & \multicolumn{3}{|l|}{ DK } & \multicolumn{3}{|c|}{ Never------Always } \\
\cline { 2 - 6 } & 0 & 1 & 2 & 3 & 4 & 5 \\
\hline $\begin{array}{l}\text { 1. Choral repetition } \\
\text { i.e. Students repeat words or phrases after the teacher }\end{array}$ & & & & & & \\
\hline 2. Minimal pair drills & & & & & & \\
\hline
\end{tabular}


i.e.Students practice the pronunciation of certain consonants or vowels using minimal pairs (i.e. e "sheet" and "seat", or "cat" and "cut")'

\section{Pronunciation-focused recast}

i.e. It refers to teachers' strategy to recast students' mispronunciation or unclear pronunciation.

\section{Back-chaining}

e.g. Teaching English word 'aroma' as 'ma' $\rightarrow$ 'roma' $\rightarrow$ 'aromal

\section{Front-chaining}

e.g. Teaching English word 'aroma' as 'a' $\rightarrow$ 'aro' $\rightarrow$ 'aroma'

6.Chanting (usually like nursery rhyme with rhythm)

\section{Reading aloud}

\section{Tongue twisters}

\section{English drama}

\section{Language laboratory}

i.e. Teachers use audio, video and web based multimedia software or device to help students to learn pronunciation

\section{Group work}

\section{Pair work}

13.Role-play/Dialogue-acting

\section{Video demonstration}

15.Imitation of native English

e.g. Taking native English( i.e. British English and American English) as the pronunciation model.

\section{Modelling the correct pronunciation}

\section{Breaking words into syllables}

e.g. Teachers teach word 'magazine' by breaking the words into 'ma'- 'ga'- 'zine'

\section{Using a chart with IPA symbols}

\section{Teaching pronunciation rules}

e.g. Most 2-syllable nouns has stress on first syllable, while most 2-syllable verbs have stress on last syllable like REcord $(N)$ and reCORD $(V)$

20.Using hands, face \& real objects to teach segmental sounds, stress and rhythm

e.g. Using fingers at the corners of the mouth - to feel the spreading and rounding of mouth for different sounds such as / $i$ :/ in 'see' vs. /o:/ in 'saw'

\section{Please add other strategies below}

21.

22.

Please list the number of number of 3 most effective strategies

1. $16 \quad 2$. $\quad 6 \quad 3$. $\quad 3$

\section{Part 4. The aspects of pronunciation that are taught in your language lesson}

Instructions: Please indicate what aspects of pronunciation you teach in your English lessons and how often you teach them. Don't know $=(0)$, Never $=(1)$, Seldom $=(2)$ Sometimes $=(3)$, Often $=(4)$, Always $=(5)$ 


\begin{tabular}{|c|c|c|c|c|c|c|}
\hline & \multirow{2}{*}{$\begin{array}{ll}\text { DK } \\
0\end{array}$} & \multicolumn{5}{|c|}{ Never----------Always } \\
\hline & & 1 & 2 & 3 & 4 & 5 \\
\hline 1. Phonetic alphabet (IPA): 24 consonants and 20 vowels & & & & & & \\
\hline $\begin{array}{l}\text { 2. Phonics knowledge } \\
\text { e.g. Knowledge of vowel digraphs 'ai' in } \underline{\text { aid, }} \text { fail, strain is pronounced as /eI/. }\end{array}$ & & & & & & \\
\hline $\begin{array}{l}\text { 3.Voiced or voiceless } \\
\text { e.g. } / g / \text { is voiced, } / k / \text { is voiceless }\end{array}$ & & & & & & \\
\hline 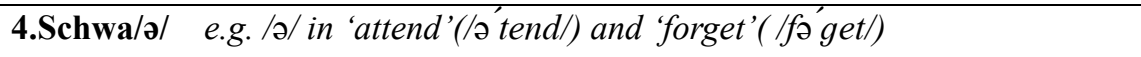 & & & & & & \\
\hline $\begin{array}{l}\text { 5. Consonant clusters } \\
\text { e.g. 'pl'in 'play', 'pr'in 'pray', and 'bl' in 'black' }\end{array}$ & & & & & & \\
\hline $\begin{array}{l}\text { 6. Allophones（音位變體） } \\
\text { e.g. There are two different /l/ sounds: clear /l/ at beginning, like in 'look' and } \\
\text { dark /l/at end, like in 'full'. }\end{array}$ & & & & & & \\
\hline $\begin{array}{l}\text { 7. Syllable structure } \\
\text { e.g. Letter ' } i \text { ' in CVC syllable is usually pronounced as /I/, like in 'sit', while } \\
\text { letter ' } i \text { ' in CVCe or CV syllable is usually pronounced as /aI/, like in 'hi' and } \\
\text { 'site' (C= consonant, } V=\text { vowel) }\end{array}$ & & & & & & \\
\hline $\begin{array}{l}\text { 8. The pronunciation rules of past-tense marker '-ed' } \\
\text { i.e. 1) /d/ after VOICED sound like in 'claimed' } \\
\text { 2) /t / after VOICELESS sounds like in 'jumped' } \\
\text { 3)/Id/ after 't'and 'd' like in 'rested' }\end{array}$ & & & & & & \\
\hline 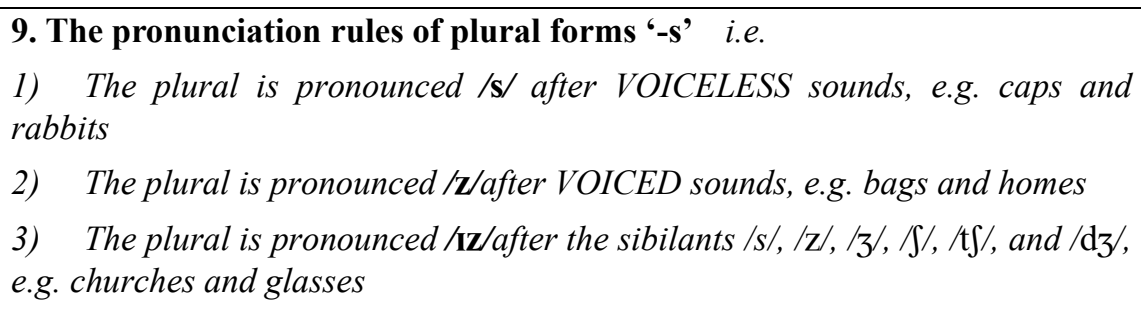 & & & & & & \\
\hline $\begin{array}{l}\text { 10. Word stress } \\
\text { e.g. In 'reLAtion', the second syllable is stressed, and in 'magaZINE' the third } \\
\text { syllable is stressed }\end{array}$ & & & & & & \\
\hline $\begin{array}{l}\text { 11. Sentence stress } \\
\text { Use sentence stress to stress the important word in sentences. } \\
\text { e.g. The KIDS are in the PARK }\end{array}$ & & & & & & \\
\hline 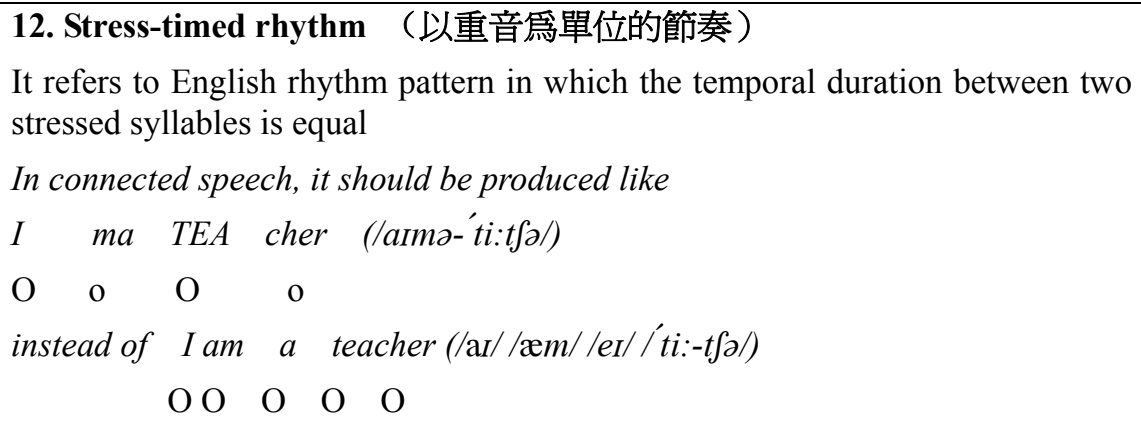 & & & & & & \\
\hline
\end{tabular}




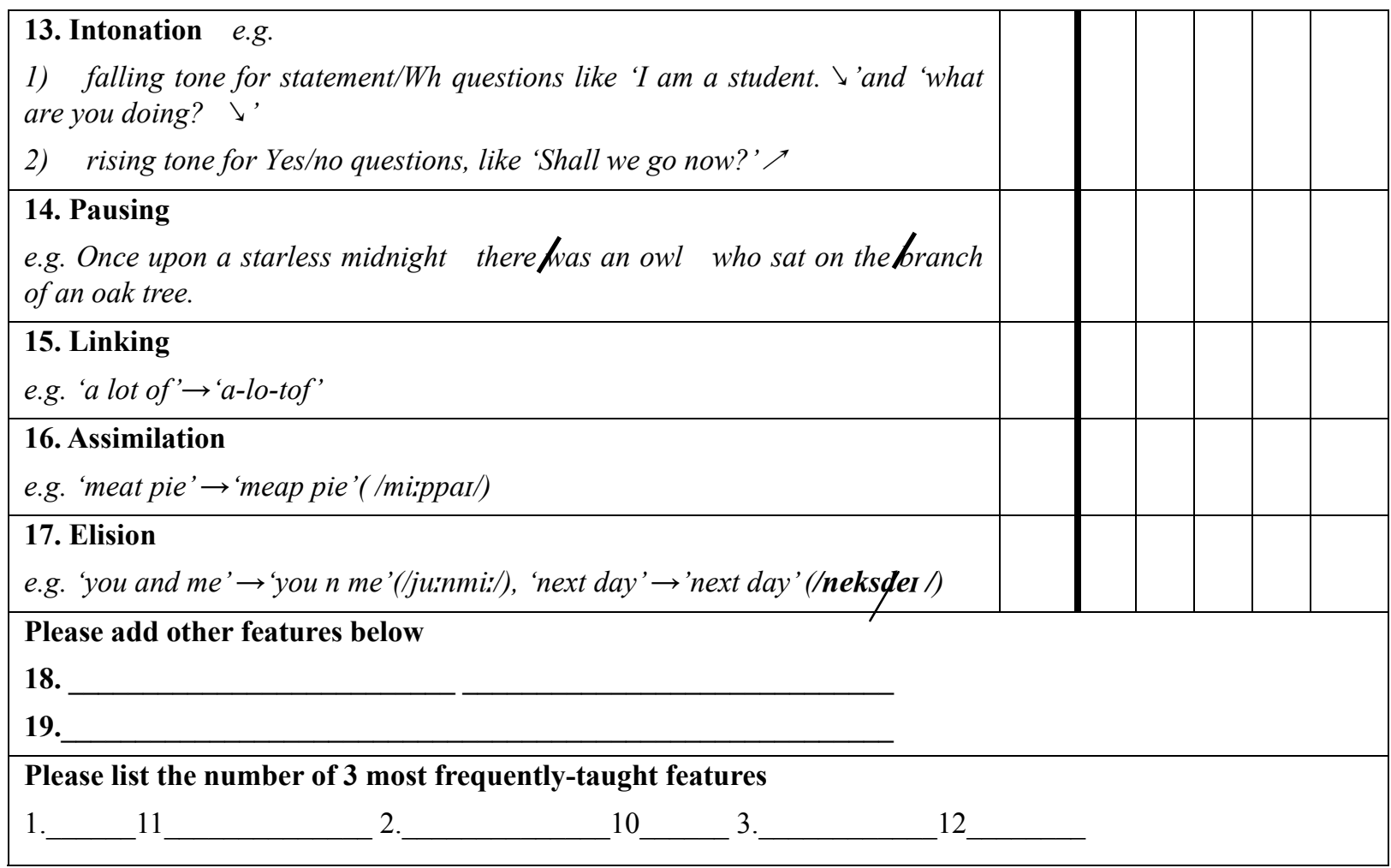

\section{Part 5. Your views on pronunciation teaching}

1. Please indicate your pronunciation teaching style/belief by ticking the appropriate items.

\begin{tabular}{|l|l|}
\hline$\square$ Proactive approach & $\square$ Remedial approach \\
\hline$\square$ Explicit & $\square$ Incidental \\
\hline$\square$ Separate lesson & $\begin{array}{l}\square \text { Integrated lesson } \\
\square \text { listening } \square \text { speaking } \square \text { reading } \\
\square \text { writing } \square \text { grammar } \square \text { Others }\end{array}$ \\
\hline$\square$ Perception(listening) & $\square$ Production(speaking) \\
\hline$\square$ Focus on fluency & $\square$ Focus on accuracy \\
\hline$\square$ Target at Intelligibility & $\square$ Target at native-like pronunciation \\
\hline $\begin{array}{l}\square \text { Focus on Suprasegmental } \\
\text { (e.g. intonation, stress, linking and ect. ) }\end{array}$ & $\begin{array}{l}\square \text { Focus on segmental } \\
\text { (e.g. consonants, vowels, and syllable structures) }\end{array}$ \\
\hline$\square$ Mini lesson :little but more often & $\square$ Whole lesson: more but less often \\
\hline
\end{tabular}

2. How do you think your pronunciation teaching has changed over your career?

Thank you again for your contribution to the inquiry. If you do not mind participating in the follow-up interview session and share your views on pronunciation teaching and intelligibility in ESL classrooms, please circle "YES" and provide your contact information below.

$\square$ YES / $\square \mathrm{NO}$

Contact information:

Name:

Email:

Phone number: 


\section{Copyrights}

Copyright for this article is retained by the author(s), with first publication rights granted to the journal.

This is an open-access article distributed under the terms and conditions of the Creative Commons Attribution license (http://creativecommons.org/licenses/by/3.0/). 